\title{
Modelos de vulnerabilidade social a desastres
}

Models of Social Vulnerability to Disasters

Modèles de vulnérabilité sociale aux catastrophes

\section{David Alexander}

Tradutor: Victor Ferreira

\section{(2) OpenEdition}

\section{Journals}

\section{Edição electrónica}

URL: http://journals.openedition.org/rccs/113

DOI: $10.4000 /$ rccs. 113

ISSN: 2182-7435

\section{Editora}

Centro de Estudos Sociais da Universidade de Coimbra

Edição impressa

Data de publição: 1 Junho 2011

Paginação: 09-29

ISSN: 0254-1106

\section{Refêrencia eletrónica}

David Alexander, «Modelos de vulnerabilidade social a desastres », Revista Crítica de Ciências Sociais

[Online], 93 | 2011, colocado online no dia 01 outubro 2012, criado a 01 maio 2019. URL : http:// journals.openedition.org/rccs/113; DOI : 10.4000/rccs.113 


\title{
DAVID ALEXANDER
}

\section{Modelos de vulnerabilidade social a desastres}

\begin{abstract}
Neste artigo discutem-se as bases teóricas da avaliação da vulnerabilidade social aos desastres e mostra-se que a vulnerabilidade é a componente mais importante do risco e o elemento principal dos impactos dos desastres. A percepção é um processo-chave na tomada de decisões em situações de desastre, sendo afectada pela cultura e pelo simbolismo, que são analisados no contexto do risco de desastres. Recorre-se a um modelo de metamorfose cultural para explicar as mudanças e as discrepâncias nas atitudes em relação aos desastres e aos processos de recuperação. A resposta ao terramoto de L'Aquila (no centro de Itália) de 6 de Abril de 2009 é analisada enquanto ilustração dos processos de metamorfose cultural e interpretação simbólica dos desastres. Essa resposta foi influenciada pelas características culturais, tanto as modernas como as herdadas, que podem ser identificadas e analisadas de modo a explicar as reacções públicas ao acontecimento. Propõe-se um novo modelo em que a cultura e a história se combinam com os perigos físicos para influenciar a vulnerabilidade.
\end{abstract}

Palavras-chave: desastres naturais; factores de risco; resiliência; sismo de L'Aquila (2009); sociologia do risco; vulnerabilidade social.

\section{Introdução}

Durante muitos anos verificou-se um desequilíbrio entre os recursos investidos na resposta aos desastres e os recursos dedicados à sua prevenção e atenuação. A comunidade mundial e a maioria dos países preferiram enfrentar o problema respondendo aos incidentes adversos ao invés de os antecipar. Existem várias razões que explicam por que é que esta posição se tornou cada vez mais difícil de manter. Em primeiro lugar, o conhecimento actual dos perigos à escala mundial é considerável, facto que se verifica também cada vez mais à escala local em muitas partes do mundo (Mercer et al., 2010). Por conseguinte, a desculpa baseada no desconhecimento já não é sustentável. Em segundo lugar, prevê-se que o número de pessoas afectadas por desastres, cerca de 280 milhões em 2010, aumente para 375 milhões em 2015 (IFRCRCS, 2010). Em terceiro lugar, é provável que as alterações climáticas venham a intensificar desastres meteorológicos como inundações e tempestades (Birkmann e von Teichman, 2010). Existem relações 
não lineares entre os factores físicos, como a velocidade média do vento ou o nível das inundações, e os danos causados, de tal forma que estes se tornam desproporcionalmente grandes relativamente à intensificação dos primeiros. Por último, em círculos políticos e diplomáticos tem havido uma tomada de consciência gradual de que os rácios benefício-custo para a redução da vulnerabilidade são tão elevados que a redução dos riscos de desastre é de toda a pertinência a nível económico. A Estratégia Internacional para a Redução de Desastres das Nações Unidas (UNISDR) e o seu Quadro de Acção de Hyogo 2010-2015 têm sido fundamentais neste processo (UNISDR, 2005). Daí que se tenha tornado difícil para os governos ignorar o problema dos desastres.

Como resultado destes factores, nos primeiros anos do novo milénio tem-se assistido a uma intensa mudança nas formas como a humanidade entende, interpreta e convive com os desastres. Desde 1970 que tem havido uma divergência cada vez maior no processo de acumulação de riqueza entre a minoria das pessoas ricas e a maioria das pessoas pobres (Massey, 1996). Ainda que a pobreza e a vulnerabilidade a desastres não sejam completamente equivalentes, estão intimamente relacionadas e, inversamente, a riqueza equivale geralmente a maior protecção e segurança. No entanto, este simples equilíbrio não reduz o potencial de perdas financeiras maciças em áreas em que tanto os perigos como o capital físico estão fortemente concentrados.

Em termos gerais, a vulnerabilidade define-se como o potencial para perdas e danos inerentes a uma pessoa ou a uma coisa (Weichselgartner, 2001). A palavra tem significados específicos em disciplinas particulares, nomeadamente no serviço social e na psicologia (Furedi, 2004). Na área dos estudos dos desastres, vulnerabilidade é a palavra-chave para a compreensão dos impactos (Birkmann, 2006). Desde o final da década de 1970 tem havido uma consciencialização gradual de que os perigos naturais, tecnológicos, sociais e intencionais (ou seja, o terrorismo) são apenas o detonador de um conjunto de reacções complexas governadas pela vulnerabilidade social, económica, cultural e física da sociedade (Hewitt, 1983). Daí que se tenha verificado uma tomada de consciência cada vez maior em relação à importância de conhecer e reduzir a vulnerabilidade humana aos desastres nas suas múltiplas e diferentes formas.

Como preâmbulo à apresentação de novos modelos para os desastres e à sua redução e gestão, na secção seguinte discutem-se as bases da teoria neste campo. 


\section{Modelos de base de redução dos riscos de desastre}

Há quem pense que a palavra "resiliência" provém dos estudos ecológicos sobre a sobrevivência das espécies (Adger, 2000), quando na verdade teve a sua origem há cerca de um século nos ensaios da mecânica dos materiais. Um material resiliente tem uma combinação óptima de rigidez - o que lhe permite resistir a uma força aplicada - e de flexibilidade - o que lhe permite absorver a força a que não consegue resistir. $\mathrm{O}$ seu ponto de ruptura ocorre a um nível bastante elevado de força aplicada (Avallone et al., 2007). Por analogia, a sociedade tem necessidade de desenvolver a capacidade de resistir às forças que causam desastres e de as absorver (ou seja, de se lhes adaptar). A resiliência social implica a reserva de fundos para futuras contingências e também a preparação para resistir a choques futuros (Manyena, 2006). Na sua base estão a prudência e a antevisão.

Caveat lector: existe uma alternativa à equação conceptual que é frequentemente empregada para explicar o risco de desastre (Alexander, 1991):

$$
\text { perigo } \times \text { vulnerabilidade }[\times \text { exposição }]=\text { risco } \rightarrow \text { desastre }
$$

Apesar de se terem acumulado tão variados tipos de riqueza material e de conhecimentos a nível mundial, ainda não se estabeleceram prioridades que permitam reduzir suficientemente o risco de desastres de modo a evitar o sofrimento e a miséria de forma maciça e generalizada. Face à propensão para gastar, alguns diriam desperdiçar, largas somas de dinheiro em empreendimentos improdutivos (por exemplo, três biliões de dólares na Guerra do Iraque), pode existir a tentação de reescrever a equação deste modo:

$$
\text { perigo } \times \text { desperdício }[\times \text { exposição }]=\text { risco } \rightarrow \text { desastre }
$$

Seja como for, a redução dos riscos de desastre deve envolver a investigação dos perigos, a protecção das populações locais, o planeamento e a preparação eficazes dos recursos, a prevenção dos riscos (sempre que possível) e a gestão dos incidentes. Os principais recursos são o conhecimento, a organização e a comunicação (Fothergill, 2000) e nenhum deles é necessariamente caro. O custo relativo das tecnologias da informação tem vindo a baixar e os mecanismos para a partilha e difusão do conhecimento têm-se multiplicado.

O conhecimento neste domínio pode ser dividido em três sectores: nos impactos do perigo, na vulnerabilidade da comunidade e nos mecanismos de defesa que produzem resiliência. É necessário evitar a tendência para relacionar o conhecimento apenas com os desastres passados em 
detrimento dos futuros. Os cenários são vitais para compreender os perigos que podem ser de algum modo antecipados, especialmente os que são recorrentes e sazonais. Todavia, um cenário não é uma projecção do passado para o futuro, é antes uma investigação de eventuais consequências futuras, recorrendo a informações obtidas a partir de incidentes anteriores (Schoemaker, 1993). A alteração das vulnerabilidades, os riscos emergentes e a intensificação dos perigos são factores que conspiram para garantir que os desastres não se repetem da mesma forma, ainda que tenham um certo grau de previsibilidade.

A redução dos riscos de desastre é, por isso, uma questão de organização e de recursos. A primeira pode ser dividida em organização imposta e em auto-organização. Destas duas, a organização imposta é mandatada pela autoridade e vem do exterior da comunidade. Inclui leis, protocolos, directivas e normas. A auto-organização envolve mecanismos de defesa próprios que a comunidade desenvolve por si mesma, incluindo o planeamento local e o trabalho voluntário (Mercer et al., 2010). Da mesma forma, os recursos podem ser divididos entre os que pertencem à comunidade $\mathrm{e}$ os que são fornecidos a partir de fora, nalguns casos ao nível da ajuda e da assistência internacional a desastres a fim de reduzir os riscos. A experiência acumulada tem mostrado que existe uma dialéctica desconfortável entre a redução de riscos de desastre própria e a imposta (Mercer et al., 2007). Em circunstâncias ideais, as melhores práticas locais são complementadas e reforçadas pela metodologia apropriada vinda de fora (Briggs, 2007). Uma tal harmonia não é fácil de alcançar e requer uma mistura de sensibilidade cultural, equilíbrio político e mero senso comum, assim como de conhecimentos técnicos e de consenso social para reduzir os desastres.

Apesar de esta ser uma necessidade presente em toda a história humana, na sua forma moderna a redução dos riscos de desastre nasce nos anos 2000 (Alexander, 2008) e entrelaça-se com duas questões que estão na ordem do dia: a resiliência e a adaptação às alterações climáticas. Além disso, responde ao imperativo da sustentabilidade. A nível mundial, o consumo de recursos está pelo menos $50 \%$ acima da capacidade de produção ou extracção, por exemplo através da prospecção de novos jazigos de petróleo, para além de que será ainda necessária uma adaptação às novas condições, que incluem temperaturas mais elevadas e subida do nível dos mares, assim como a acontecimentos naturais potencialmente mais intensos que causam desastres (UNISDR, 2009). Estes são alguns dos motivos para defender uma resposta sustentável.

Os desastres podem travar o desenvolvimento. Na Nicarágua, por exemplo, estima-se que os estragos causados pelo furacão Mitch, em 1998, 
tenham provocado um atraso de 20 anos no desenvolvimento (Wisner, 2001). Daí que a redução dos riscos de desastre faça parte da agenda do desenvolvimento sustentável. No entanto, a sustentabilidade é uma questão controversa e não existe uma definição única do termo sustentável. Todavia, é consensual que a sustentabilidade requer um nível de harmonia entre os seres humanos e a natureza, bem como alguma conservação da base de recursos naturais (Saunier, 1999). A redução dos riscos de desastre pode contribuir para os processos envolvidos. Além disso, há questões de sustentabilidade directamente relacionadas com a redução dos riscos de desastre. Houve programas que falharam por causa da falta de financiamento consistente, de objectivos pouco claros ou inadequados e de falta de apoio político ou social. Em síntese, os programas sustentáveis de redução dos riscos de desastre assentam na governação, definida aqui como uma forma participativa de democracia na qual as instituições têm apoio público e as partes interessadas têm a capacidade de se envolverem directamente nas tomadas de decisão. A governação está na raiz da redução da vulnerabilidade, da preparação para os desastres e do desenvolvimento de mecanismos de defesa (Ammann, 2006).

Estas observações constituem um quadro simples para analisar as respostas humanas à ameaça e ao impacto dos desastres. Contudo, é necessária uma nova teoria. Grande parte do actual corpo teórico tem por base as ideias de ecologia cultural, ou de ecologia humana, difundidas na década de 1920 e desenvolvidas na sua grande maioria na década de 1960 (White, 1974). Desde então houve enormes mudanças na sociedade, na economia e no ambiente. Além disso, o passo acelerado da mudança global altera ainda mais os parâmetros da teoria. Por exemplo, a revolução das tecnologias da informação tem sido comparada à invenção da imprensa (Quarantelli, 1997), tendo provocado um impacto profundo em muitas e diferentes formas de actividade humana e de relações sociais. Para podermos compreender os desastres no século XXI é necessário procurar novas formas de explicação, novos modelos que sejam capazes de desvendar a complexidade de um meio que muda rapidamente. A teoria desenvolvida nas décadas de 1960 e 1970 já não é capaz de o fazer.

\section{Para uma nova base teórica para os estudos dos desastres}

O mundo moderno caracteriza-se por desequilíbrios cada vez maiores no acesso à riqueza e aos recursos, na segurança e nas oportunidades de prosperar (Massey, 1996). A má utilização dos recursos e a ênfase excessiva no desenvolvimento económico sem ter em conta a totalidade dos custos podem exacerbar estes desequilíbrios. Uma nova teoria precisa de ser capaz de 
descrever e interpretar esta situação, assim como de responder às mudanças profundas que estão a ocorrer na interconexão global.

A ecologia humana pressupõe uma relação entre as pessoas e o seu ambiente em que a tecnologia possa superar algumas das dificuldades, mas a natureza não é facilmente dominada, sendo necessária uma adaptação aos extremos (White, 1974). Na formulação original, o modelo é baseado no trabalho de Herbert Simon sobre o homem racional que toma decisões económicas com vista à optimização, maximizando as oportunidades para recolher informações, ou com vista à mera satisfação das necessidades, escolhendo racionalmente a partir de uma gama limitada de opções (Simon, 1956). Evidentemente, este modelo não deixa margem para variações culturais ou ideológicas e apenas permite oportunidades muito limitadas no que toca à escolha. Na verdade, verifica-se uma dialéctica constante entre factores que aumentam o risco (por exemplo, furacões mais fortes, construção de novas urbanizações em áreas vulneráveis, gestão da água que aumenta o risco de cheias a jusante) e os que o diminuem - as acções de atenuação dos riscos de desastre. Esta dialéctica é ainda influenciada pela percepção do risco, que tanto pode aumentar como diminuir a vulnerabilidade, dependendo do seu nível de relevância ou de exactidão. Por isso, em termos esquemáticos:

\section{Vulnerabilidade total aos desastres $=$ \\ Processos de amplificação do risco- \\ Processos de atenuação do risco \pm \\ Factores de percepção do risco}

Na redução dos riscos de desastre, as decisões, as acções e os resultados dependem todos de uma interacção complexa entre a percepção e a cultura.

\section{A importância da cultura e do simbolismo na redução dos riscos de desastre} Surpreendentemente, poucos estudos académicos abordam o problema da cultura (Gheradi, 1998). O termo pode ser definido como um conjunto de crenças, opiniões, características sociais e atitudes partilhadas. A cultura é extremamente difícil de medir em termos científicos ou científico-sociais (Brislin, 1980). Tratando-se de um conceito ambíguo e multifacetado, muda com o contexto social. Para além disso, e tal como as caixas chinesas ou as bonecas russas, a cultura consiste num conjunto de fenómenos encaixados uns nos outros: reagimos a diferentes culturas relacionadas com enquadramentos nacionais, regionais e locais determinados; com grupos de pares, famílias e locais de trabalho; com grupos étnicos e sociais; com sexo e raça; e com grupos de interesses. Finalmente, a cultura sofre um processo constante 
de metamorfose à medida que se adapta às alterações de circunstâncias do mundo moderno e ao modo como somos capazes de o interpretar. Por conseguinte, existem poucas formas fiáveis de medir a cultura. Ainda assim, a cultura é extremamente importante. Se se pretende promover a mudança, é mais provável que ela seja bem-sucedida se for compatível com a cultura predominante, ao passo que se for contra ela é provável que o processo adaptativo seja bloqueado por razões aparentemente ilógicas.

Cada um de nós herda um contexto cultural que é mais ou menos evidente, dependendo da solidez dos laços a lugares e a grupos sociais específicos. Passamos as nossas vidas a acumular características culturais através de processos de aprendizagem e assimilação. Estes são os componentes émicos da cultura - aqueles que são específicos de um contexto cultural particular. Os aspectos éticos estão relacionados com características universais e são a fonte de muita metamorfose cultural. $\mathrm{Na}$ época actual eles são, na sua maioria, o resultado da difusão da cultura de massas e da tecnologia que a dissemina. Por conseguinte, o moderno funde-se com tradições culturais antigas: simbioticamente, o primeiro é interpretado à luz das segundas (Figura 1).

A Figura 1 ilustra o facto de a cultura não ser um fenómeno estático, mas sim um fenómeno que contém em si o seu próprio dinamismo. No entanto, não nos devemos iludir com os seus aspectos dinâmicos, nomeadamente a cultura do consumo de massas inerente aos aspectos éticos ou universais da vida moderna.

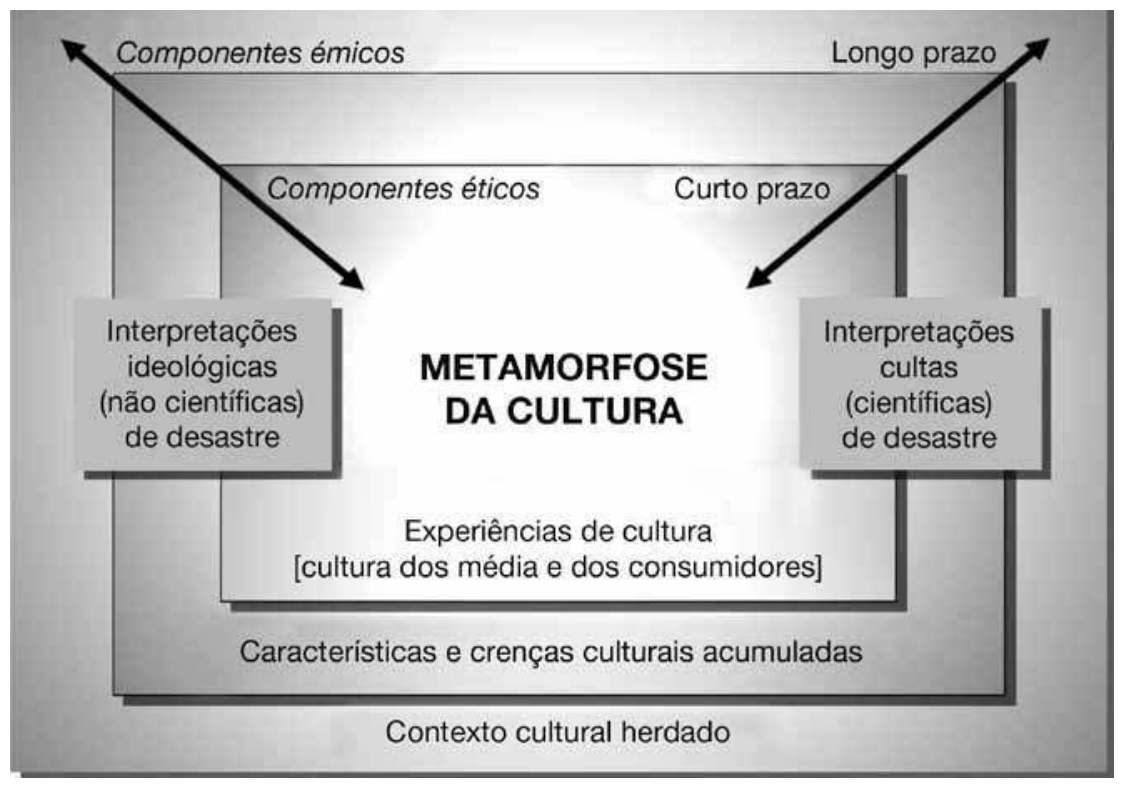

FIGURA 1 - A arquitectura e a metamorfose da cultura humana 
Estes aspectos são fontes importantes de uniformidade cultural no mundo moderno, mas devemos lembrar-nos que por debaixo deles existem características acumuladas e herdadas que também são capazes de influenciar as nossas atitudes e respostas aos desastres. Na próxima secção veremos como a resposta ao terramoto de 6 de Abril de 2009 em L'Aquila, no centro de Itália, demonstra um desejo súbito e quase espontâneo de modernidade, tal como é evidenciado pelas formas de reconstrução, que revelam uma ruptura clara com a forma urbana tradicional. Pelo contrário, as relações de poder ao nível político que condicionaram as escolhas feitas no processo de reconstrução reflectem mais o peso da história, os processos émicos de um tecido social que é lento a evoluir, do que os processos éticos que se encontram no modernismo.

A cultura é importante para qualquer entendimento do significado e do papel dos desastres no mundo moderno, uma vez que determina a forma como a percepção é interpretada, podendo mesmo determinar o que é apercebido. Assim, compreendemos os desastres através de um filtro perceptual e cultural que tem muitos níveis, desde o individual - através da família, de grupos de pares, de organizações, da comunidade, da região e da nação até às formas éticas internacionais da cultura popular. A título de exemplo, as formas de redução de desastres baseadas na comunidade devem ter em conta o modo como os membros dessa comunidade se associam uns aos outros, incluindo a sua forma própria de se reunirem e de debaterem os problemas (a socialização do problema), as estruturas de poder que a constituem e os pontos de origem da autoridade. Todos estes elementos são, até certo ponto, culturalmente determinados.

Neste contexto, os estudiosos dos desastres têm ignorado em grande medida o papel dos símbolos e do simbolismo. Estes têm sido importantes ao longo da história e continuam a ser relevantes actualmente, ainda que num contexto radicalmente diferente (Alexander, 2004). No passado, o aparecimento de um cometa no céu podia ser interpretado como um presságio de condenação e de destruição. Hoje em dia, os símbolos são a forma mais simples de representar uma realidade que se torna progressivamente mais complexa à medida que existe cada vez mais informação disponível. Os símbolos e o simbolismo constituem uma resposta natural ao domínio da comunicação pelas representações electrónicas da realidade, muitas das quais são seriamente redutoras.

Uma consequência da revolução das tecnologias da informação tem sido a alteração da interpretação simbólica dos desastres. Há sessenta anos, estar envolvido num desastre era, em muitas culturas, estar sujeito a uma forma de vergonha de que dificilmente se podia falar. Actualmente, este tipo de 
situação foi radicalmente transformado pela atenção dos meios de comunicação social. Ser vítima de um desastre pode inclusivamente constituir uma via para a celebridade. Isto tem a ver com a interpretação - simbólica - dos desastres como forma de ultraje moral (Horlick-Jones, 1995), em que a vítima adquire a força da autoridade moral simplesmente por estar envolvida. Porém, para que isto seja verdade, muito depende do "valor da história" (ou seja, da singularidade, novidade, interesse humano, etc.) que os meios de comunicação social atribuem à situação e aos protagonistas.

É bem possível que a chave para a interpretação dos desastres se encontre nos trabalhos de Carl Gustav Jung ("o ser humano e os seus símbolos", 1964), Roland Barthes ("semiótica e mito", 2009), Umberto Eco ("semiótica e cultura popular", 1978) e Zygmunt Bauman ("modernidade líquida", 2001). É possível que os três ramos da semiótica estejam envolvidos neste processo. Primeiro, a semântica, a relação entre os signos e os denotata - as coisas a que aqueles conferem significado -, pode ajudar-nos a compreender o fosso existente entre a percepção do perigo, do risco e do desastre e a existência desses acontecimentos em termos científicos. Em trabalhos anteriores enumerei 47 equívocos comuns sobre o desastre e analisei a forma como alguns deles influenciam o julgamento das pessoas envolvidas na gestão de emergências. Segundo, a sintáctica, a relação entre os signos em estruturas formais, pode ajudar-nos a compreender o modo como a representação dos desastres está codificada pelos grupos e pelas culturas envolvidas. Isto é a interpretação abreviada do risco e do impacto para efeitos da reacção rápida, a linguagem da resposta ao perigo. Em terceiro e último lugar, a pragmática, as relações entre os signos e o seu efeito nas pessoas que os usam, pode ajudar-nos a entender o retorno entre as representações simbólicas dos desastres, dos riscos e dos incidentes extremos e os significados que resultam destes modelos e que os geram.

Passando agora à discussão específica sobre os conceitos de vulnerabilidade e de risco, é necessária uma advertência. Os estudiosos dos desastres deverão ter-se apercebido de que a interpretação do risco das ciências "duras" é fundamentalmente diferente da interpretação das ciências sociais (Slovic e Gregory, 1999). Normalmente, o risco na engenharia envolve o cálculo da probabilidade de colapso, sob condições específicas de carga, de uma estrutura construída. Já o risco nas ciências sociais coloca em jogo factores dificilmente quantificáveis, como a percepção, ou factores cuja tentativa de quantificação leva a resultados insatisfatórios (Purchase e Slovic, 1999). Por isso, o risco e a sua componente dominante, a vulnerabilidade, são essencialmente conceitos hipotéticos. Paradoxalmente, não são menos reais por serem hipotéticos. Contudo, logo que se convocam são 
instantaneamente transformados em impacto. Assim, não é de admirar que o risco e a vulnerabilidade permaneçam conceitos ambíguos - mas não ilusórios - que desafiam a medição ou a avaliação holística. Para compreender ambos, é necessário descer ao nível da estimativa parcial, recorrendo a um conjunto de condições de qualificação - por exemplo, o risco ao longo de períodos definidos de tempo e relativamente a um sector, como a actividade económica ou a infecção e a doença.

Infelizmente, muitas das ideias atrás expressas estão apenas parcialmente desenvolvidas. O seu desenvolvimento completo requer uma observação maior e mais incisiva durante períodos mais longos de tempo. Além disso, esses períodos serão inevitavelmente caracterizados por mudanças rápidas e profundas na sociedade e no meio ambiente. Apesar de tudo, é possível dar início à interpretação da realidade actual usando novos modelos. $\mathrm{Na}$ próxima secção será apresentado um pequeno exemplo.

\section{Interpretações do sismo de L'Aquila (centro de Itália) de $\mathbf{6}$ de Abril de 2009}

Às 3h32, hora local, de segunda-feira, 6 de Abril de 2009, ocorreu um sismo de magnitude $\mathrm{Mw}=6,3$, com uma duração de 25 segundos, uma aceleração média de pico de $0,3 \mathrm{~g}$ e epicentro a $3,4 \mathrm{~km}$ do centro de L'Aquila, uma cidade de 72800 habitantes, localizada na cordilheira dos Apeninos, na região de Abruzzo, no centro de Itália. No total morreram 308 pessoas, 1500 ficaram feridas, 202 das quais gravemente, 67000 ficaram desalojadas e cerca de 100000 edifícios foram seriamente danificados. Este sismo integrou uma intensa actividade sísmica com início em Outubro de 2008 e que só abrandou no Verão de 2009. L’Aquila já tinha sido atingida por um sismo devastador em 1703, de que resultaram entre 6000 a 10000 mortos, mas o último grande sismo na região de Abruzzo ocorreu em 1915, em Avezzano, a cerca de $100 \mathrm{~km}$ a sudeste de L'Aquila. Morreram 32000 pessoas, incluindo $94 \%$ da população de Avezzano. O número de vítimas mortais em 2009 poderia ter sido muito superior, não se tivesse dado o caso de o sismo ter ocorrido durante um fim-de-semana prolongado em que muitas pessoas estavam fora.

O sismo de L'Aquila foi um incidente físico moderado, mas devido aos elevados níveis de vulnerabilidade sísmica teve um impacto completamente desproporcionado sobre a população da área afectada, com 16 municípios severamente atingidos, de um total de 98 afectados, 49 dos quais com gravidade. Este desastre foi, pois, um teste significativo para o sistema de protecção civil italiano, que respondeu com uma grande mobilização dos recursos nacionais. Perante o risco de colapso estrutural dos edifícios desestabilizados pelo sismo, a cidade de L'Aquila e várias outras vilas da área foram fechadas 
à população, tendo sido a primeira vez na história da Itália moderna que uma cidade desta dimensão foi completamente evacuada, demais a mais durante um período que excedeu um ano (Stucchi et al., 2009).

$\mathrm{Na}$ altura do sismo, o salvamento dos sobreviventes foi dificultado pelo colapso parcial do principal hospital regional, San Salvatore, o centro médico mais bem adaptado para respostas de emergência a uma situação com um número elevado de vítimas. Nas primeiras 24 horas entrou em serviço o primeiro de dois grandes hospitais de campanha montados nas proximidades, mas algumas horas depois do sismo foi necessário evacuar o hospital San Salvatore por receio de colapso estrutural. Por isso, a resposta médica imediata foi levada a cabo por unidades militares de evacuação médica, que transportaram os doentes mais graves por via aérea para os hospitais mais próximos, a maioria dos quais a uma distância considerável de L'Aquila.

Dos 67000 sobreviventes que ficaram desalojados, cerca de 21000 ficaram em 171 acampamentos, na maioria em tendas para oito pessoas. Um número idêntico foi alojado em hotéis, muitos deles na costa do Adriático, a oeste da cordilheira dos Apeninos. Os restantes arranjaram acomodação por sua conta ou deixaram a região. Os acampamentos mantiveram-se durante seis meses, até ao final do Verão, quando foram substituídos por habitações provisórias. Estas eram de dois tipos: CASE (Complessi Antisismici Sostenibili ed Ecocompatibili-Complexo Anti-Sísmico Sustentável e Ecocompatível) e MAP (Moduli Abitativi Provvisori-Módulos Habitacionais Provisórios). O projecto CASE consistiu em 184 unidades de ocupação múltipla, com isolamento sísmico de base, construídas em 19 locais nas proximidades de L'Aquila (Figura 2). As unidades MAP eram pequenos módulos pré-fabricados sem isolamento de base, que foram montados em mais de 50 locais na zona. Foram alojadas 15500 pessoas nas unidades CASE e 8500 nos módulos MAP (Calvi e Spaziante, 2009).

As estratégias imediatas e de curto prazo do governo italiano para a gestão do desastre provocado pelo sismo incluíram a doutrina da força esmagadora (Alexander, 2010). Reuniu-se rapidamente um elevado número de veículos e uma quantidade imensa de materiais para resolver os problemas do isolamento das áreas destruídas, do reforço dos edifícios em estado precário, da alimentação e realojamento das populações desalojadas e de coordenação do afluxo de bens de primeira necessidade e de pessoal para prestar ajuda. Como é hábito, os serviços de bombeiros italianos constituíram o órgão de direcção. Os serviços de emergência e as centenas de organizações voluntárias de protecção civil foram coordenados pelo Departamento Nacional de Protecção Civil. A estratégia foi bem-sucedida, 


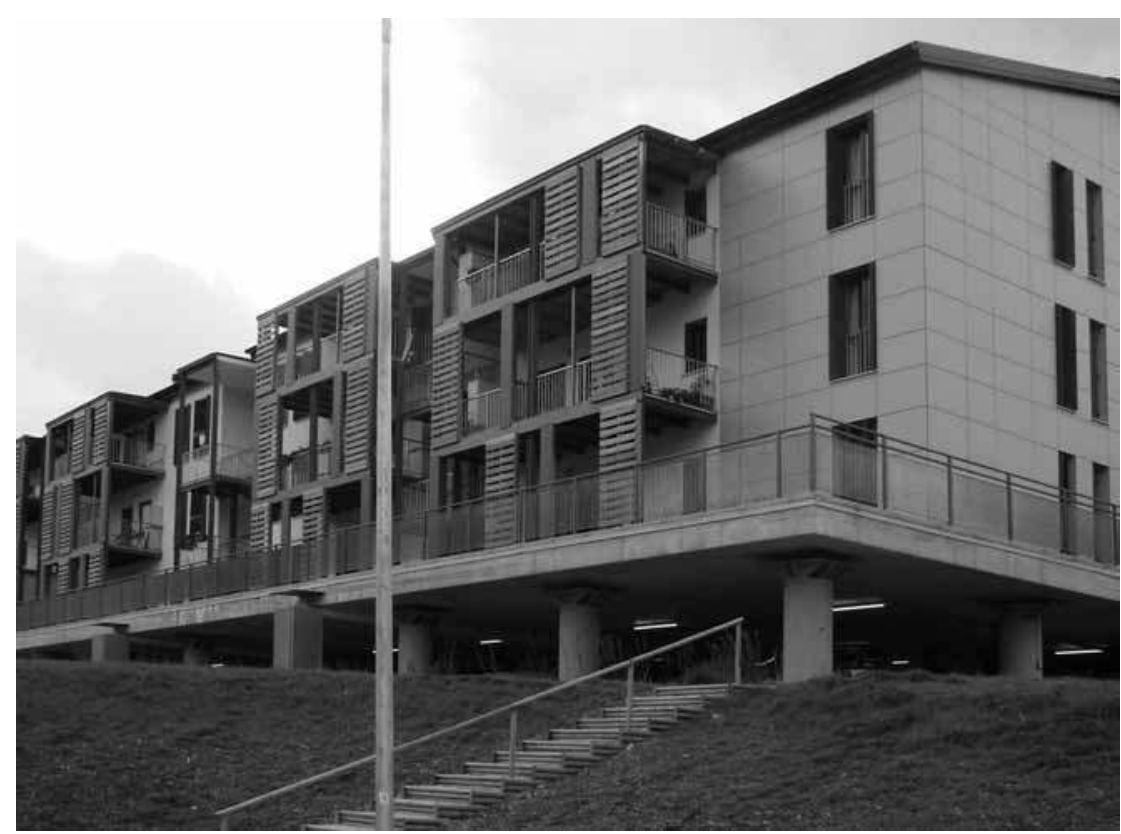

FIGURA 2 - Habitações provisórias CASE em Bazzano, arredores de L'Aquila (foto do autor) As colunas do isolamento de base suportam o edifício e protegem-no das oscilações sísmicas

mas falta saber se este tipo de medida pode ser adoptado no caso de um sismo de maior magnitude que afecte uma área significativamente maior e uma população em número muito superior.

A estratégia de médio prazo é ainda mais controversa. Por causa dos estragos nas casas tradicionais, os desastres sísmicos envolvem uma quantidade maciça e súbita de desalojados. A estratégia mais comum para lidar com a situação é o recurso a tendas e abrigos improvisados durante um período de tempo muito curto (uma questão de dias ou de muito poucas semanas) e posteriormente disponibilizar habitações provisórias baratas, mas sólidas, com recurso a casas-contentores ou a pequenos pré-fabricados com paredes leves, com áreas com cerca de 30 a $40 \mathrm{~m}^{2}$, sendo atribuída uma habitação por família (Aysan e Davis, 1992).

O custo deste tipo de habitação anda à volta de 12000 a $15000 €$ por unidade, incluindo os requisitos mínimos essenciais ao nível da urbanização dos locais e da construção de redes temporárias para a distribuição de serviços de utilidade pública. Em L'Aquila, o custo das unidades CASE atingiu $3750 €$ por metro quadrado, uma média de $280607 €$ por unidade familiar (Calvi e Spaziante, 2009), o equivalente a um apartamento comparável numa grande cidade. Simultaneamente, gastou-se muito dinheiro 
na consolidação intensiva dos edifícios afectados no centro das povoações, que continuaram vedadas ao acesso do público. Contudo, o governo já não conseguiu meios para remover 4 a 5 milhões de toneladas de entulho que se estima que estejam nesses locais. As unidades CASE não corresponderam à sua designação de "ecocompatíveis", pois embora tenham painéis solares para aquecimento da água, a falta de serviços e de transportes públicos provocou uma enorme dependência em relação ao uso do automóvel particular, aumentando a pegada ecológica dos residentes desses novos alojamentos.

Entretanto, nada foi feito para melhorar as infraestruturas locais ou o acesso a serviços. Também não houve relançamento da economia. Por isso verificou-se a estagnação desta, a migração de trabalhadores para outras zonas e a perda de 16000 a 26000 empregos como resultado directo da destruição de lojas, estúdios e empresas pelo sismo. Além disso, ficou demonstrado que a devolução de impostos às regiões, uma política tão entusiasticamente promovida pelos governos italianos desde a década de 1990, se revelou vantajosa para algumas regiões de Itália, mas para outras teve um efeito fiscalmente regressivo. L'Aquila é a mais afectada pela segunda situação.

É difícil analisar a estratégia global do governo italiano para lidar com o sismo de L'Aquila, excepto em termos políticos. Em meados de 2009, o primeiro-ministro, Silvio Berlusconi, afectado por escândalos e pela perda de popularidade, comprometeu-se a realojar no prazo de seis meses todas as famílias desalojadas por causa do sismo. Assim, estas permaneceram em tendas durante o longo Verão e logo que as temperaturas desceram, no Outono, foram realojadas nas unidades CASE e MAP, que entretanto tinham sido rapidamente construídas. Foi uma proeza logística assinalável, que envolveu pouca ou nenhuma perda de qualidade entre a concepção e a conclusão de todas as casas. Este facto deu ao governo e ao primeiro-ministro uma vantagem política significativa, habilmente explorada de modo a ganhar votos nas eleições locais e regionais.

No entanto, a concretização do realojamento teve um preço muito elevado. Para começar, as habitações provisórias custaram mais de 20 vezes o que teriam custado soluções mais económicas. Em segundo lugar, não houve qualquer investimento em transportes e serviços, deixando locais com populações até cerca de 2500 pessoas sem lojas, centros comunitários, cafés, serviços de transportes públicos, centros de saúde, escolas e consultórios médicos. Além disso, foi dada pouca atenção ao problema da manutenção da coesão social, aquando da atribuição das unidades habitacionais provisórias. Isto levou a elevados níveis de isolamento, depressão e stress 
pós-traumático entre as pessoas a que foram atribuídas estas habitações. Em conclusão, os enormes gastos com a consolidação dos edifícios e com as habitações provisórias deixaram muito pouco ou nada para a reconstrução. $\mathrm{O}$ aspecto físico destas duas iniciativas sugere que o governo preparou o caminho para um longo intervalo, talvez de décadas, antes de se iniciar a reconstrução - se esta alguma vez vier a ocorrer. Esta situação já tem um precedente no Vale de Belice, na zona ocidental da Sicília, outro lugar remoto, que sofreu 15 anos de estagnação entre os sismos de 1968 e a inauguração de uma quantidade significativa de casas reconstruídas e de serviços urbanos (Angotti, 1977).

O simbolismo político de dar uma habitação digna aos desalojados não pode ser subestimado. O governo italiano forneceu tudo, incluindo o mobiliário, talheres, loiças, toalhas, roupa de cama, televisões e electrodomésticos. O modelo foi Milano Due, o empreendimento residencial especulativo em Segrate, Milão, construído de 1970 a 1979, e que projectou Silvio Berlusconi da obscuridade para a notoriedade nacional. Esta prodigalidade conquistou votos instantaneamente, mas o paternalismo do Estado destruiu a governação, no sentido pretendido pela definição dada anteriormente neste texto. A divergência é pouco tolerada e L'Aquila tornou-se mais uma vez política, económica e socialmente marginalizada na vida nacional. A tirania da geografia é tal que, apesar de ficar a pouco menos de $120 \mathrm{~km}$ do centro de Roma, L'Aquila está situada numa bacia intramontanhosa com ligações relativamente fracas a outras partes de Itália. A sua principal fonte de emprego é a universidade local, numa altura em que o ensino superior em Itália está num estado de grave depressão.

Em L'Aquila, o protesto e a divergência política têm sido tratados pelas forças governamentais com recurso à violência e à intimidação. A tributação tem sido inimiga das empresas. Houve grupos que emergiram, mas não atingiram a massa crítica ou a notoriedade necessária para terem muita influência numa situação caracterizada por estagnação e declínio. $\mathrm{O}$ contexto cultural ancestral da área caracteriza-se pela pobreza e pela dependência feudal. Ainda que já não haja pobreza absoluta, permanecem traços de dependência pessoal e familista, juntamente com a depressão económica de uma região a que não foram dados os melhores incentivos possíveis para crescer e desenvolver os seus já de si escassos recursos. Ainda que as crónicas da miseria na área rural não sejam de modo algum um diagnóstico das condições modernas, existem paralelos no contexto cultural herdado, em particular no conservadorismo de um povo que durante muito tempo teve muito a perder se protestasse (Russo, 1955). A maior vítima é a boa governação e a eventual prosperidade que dela poderia ter resultado. 
Uma característica das sociedades tradicionais parece ser a situação particular das mulheres. Ainda que a situação em L'Aquila não seja tão grave como a que ocorre em muitos países, o sismo produziu, no entanto, um viés de género claramente perceptível (cf. Enarson e Morrow, 1998). Morreram mais mulheres do que homens, especialmente nos grupos etários dos 30 aos 39 e acima dos 70. Mesmo quando se faz a correcção tendo em conta o desequilíbrio demográfico entre os sexos na população idosa, a anomalia permanece (Alexander, 2011). É difícil formular uma explicação, mas é possível que esta esteja relacionada com a menor mobilidade das mulheres em relação aos homens: provavelmente alguns homens registados como residentes na área não estavam fisicamente presentes na noite do sismo. Seja qual for a explicação, alguns estudos revelam que as mulheres também sofreram mais stress pós-traumático do que os homens durante os meses subsequentes ao sismo (Dell'Osso et al., 2011).

O sismo de L'Aquila e as suas consequências estão abertos a várias formas de interpretação simbólica. Para começar, trata-se do primeiro grande teste ao actual sistema de protecção civil italiano desde o sismo de 1980 no Sul de Itália. Reflectiu, neste caso, a competência do país perante uma emergência grave de origem natural. Em segundo lugar, o desastre foi ofuscado por considerações políticas, à luz da necessidade de o governo italiano ganhar popularidade a curto prazo por razões eleitorais de modo a manter a sua base de poder. A cimeira do G8 realizada em L'Aquila, de 8 a 10 de Julho de 2009, representou o pico deste processo. Na verdade, a cimeira pouco fez pela situação dos habitantes de L'Aquila, mas esteve impregnada de momentos simbólicos. Por exemplo, a povoação mais afectada pelo sismo foi Onna, em que morreram 40 dos seus 300 habitantes quando 60\% dos edifícios ruíram. No dia 11 de Junho de 1944, Onna foi palco do massacre de 18 dos seus habitantes civis pelas tropas alemãs e, durante a cimeira, o ministro alemão dos Negócios Estrangeiros comprometeu-se com ajuda financeira para a reconstrução, um gesto extremamente simbólico à luz das movimentações actuais no sentido da unidade europeia.

Tal como muitos desastres modernos, o sismo de L'Aquila foi um drama tratado pelos média, em especial a televisão, que manteve uma presença constante no local durante semanas. A solidariedade moderna pós-desastre tem uma face bastante pública, num grande contraste com épocas anteriores (Alexander, 2006). No entanto, o problema da cobertura mediática é que não apresenta necessariamente um retrato consistente e preciso da realidade no terreno, já que muda muito mais de dia para dia do que aquilo que acontece na realidade. Além do mais, muitos dos problemas mais graves, nomeadamente a estagnação burocrática, não são propriamente mediáticos. 
Pelo contrário, foi fácil interpretar o desastre em termos, por exemplo, da caridade, da piedade e da compaixão inerentes ao catolicismo, um dos principais subtextos culturais.

Por último, apesar da estagnação económica, da inexistência de trabalhos de reconstrução e da ausência de melhorias na infraestrutura local, verificaram-se algumas transformações assinaláveis na zona de L'Aquila. Por exemplo, durante séculos a construção na região foi dominada pelo uso da pedra, tendo entretanto sido incorporado o betão armado (obviamente com resultados contraditórios em termos de resposta sísmica). De um momento para o outro, na sequência do sismo, houve uma enorme adesão à construção em madeira e aço, muita dela organizada em zonas residenciais à maneira anglo-saxónica. Simbolicamente, isto pareceu representar uma modernização repentina de uma zona bastante antiga (a cidade de L'Aquila tem 1000 anos e muitas das povoações circundantes têm o dobro da idade) ou pelo menos um desejo de modernização. Face ao paternalismo e à ausência de governação, quase que se lhe pode chamar uma modernização forçada. Em casos como este existe o risco de se vir a destruir a alma do lugar - genius loci - adquirida ao longo de séculos. Em Itália, os povoamentos históricos dependem, em termos da sua identidade, de um número de monumentos icónicos e de um tipo distintivo de forma urbana. A supressão de qualquer um deles só iria desligar as pessoas da sua história e diminuir o seu sentido de identidade social. Haveria, portanto, discórdia na semântica da análise semiológica e, provavelmente, também na pragmática (Eco, 1978).

Muito mais poderia ser feito para interpretar a situação em L'Aquila em termos semiológicos e a matéria-prima está, sem dúvida, disponível. Contudo, para tal é necessário aguardar por mais investigação e entretanto é necessário tirar algumas conclusões.

\section{Conclusão: Modelos sociais de desastre}

Os primeiros modelos ecológicos de desastre eram de concepção linear. O perigo actuava na vulnerabilidade para produzir desastres. Daí decorria que, uma vez que os perigos estavam no início do processo, eram eles que recebiam a parte de leão da atenção. Isto também estava em linha com o predomínio na altura das ciências físicas em relação às sociais. No período de 1979 a 1983, os investigadores que trabalhavam nos países em desenvolvimento produziram a chamada "crítica radical", que defendia que a vulnerabilidade tem mais peso do que o perigo na explicação do desastre (Hewitt, 1983). Em resultado de ciclos de retroacção, o perigo pode ser encarado como o detonador de processos sociais que geram vulnerabilidade, que é causa determinante do potencial de desastre. 
O conhecimento cada vez maior dos desastres e dos processos sociais envolvidos e a crescente complexidade da vida no início do século XXI sugerem que se deve formular um novo modelo (Figura 3). Os perigos físicos (sejam naturais ou antropogénicos), assim como os factores culturais e históricos, actuam em conformidade com a vulnerabilidade dos sistemas socioeconómicos humanos. O plexo do contexto e as consequências destas associações é o que determina a forma, a entidade e a dimensão de qualquer desastre subsequente.

Modelo "Linear"

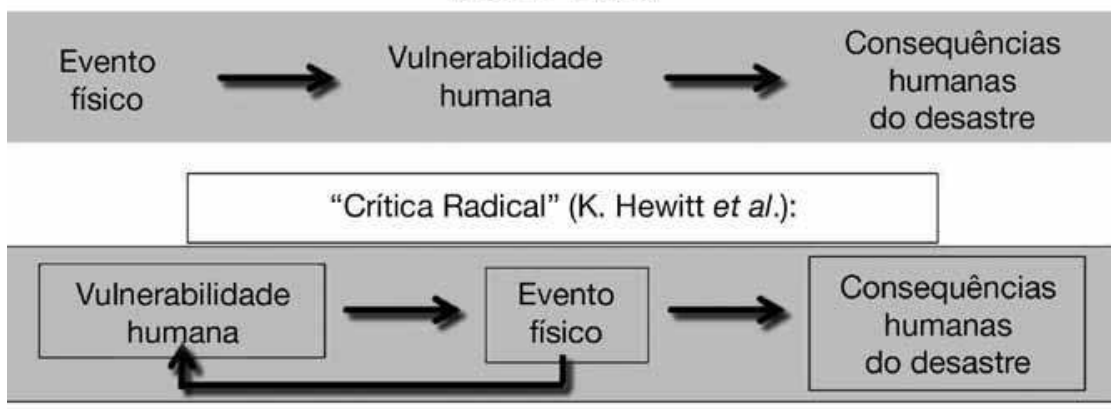

Proposta para um novo modelo

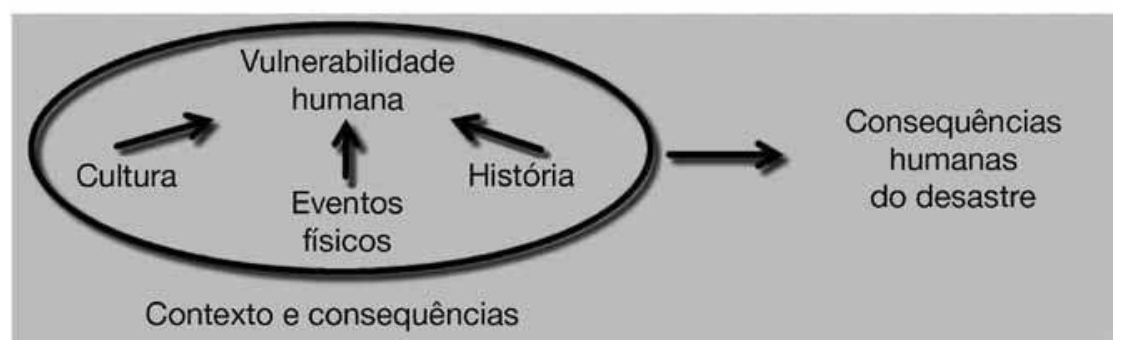

FIGURA 3 - Possível evolução dos modelos de desastre

É óbvio que este constitui um modelo preliminar e esquemático. Há ainda muito trabalho a fazer, de forma a que se possam introduzir os pormenores e clarificar as relações. Por exemplo, a história é um factor explicativo vital (e vivemos numa época propensa a esquecer as suas lições), mas não determina o futuro, apenas contribui com alguns ingredientes importantes. Será necessário que seja acompanhada de muita reflexão, para que seja possível interpretar os desastres criativamente com um discernimento incisivo. As tendências terão de ser compreendidas e incorporadas neste processo, dado que vivemos num mundo que está a consumir recursos a um ritmo acelerado, que está a sofrer uma mudança ambiental a uma velocidade 
ainda maior e que está a ficar cada vez mais lotado com pessoas que vivem, viajam e trabalham em zonas perigosas. Qualquer explicação válida e viável dos desastres para o novo milénio tem de incluir as consequências das mudanças tecnológicas, que alteraram radicalmente a nossa perspectiva e interpretação dos desastres. Daí que estejamos perante um desafio intelectual e prático que merece ser enfrentado, uma vez que a teoria é o "roteiro" pelo qual navegamos através do caos das situações de desastre e de risco e que nos permite geri-las.

Tradução de

Victor Ferreira

\section{Referências bibliográficas}

Adger, W. Neil (2000), "Social and Ecological Resilience: Are they related?", Progress in Human Geography, 24(3), 347-364.

Alexander, David E. (1991), "Natural Disasters: A framework for research and teaching", Disasters, 15(3), 209-226.

Alexander, David E. (2004), "An Interpretation of Disaster in Terms of Changes in Culture, Society and International Relations”, in R.W. Perry e E. L. Quarantelli (orgs.), What is a Disaster? New Answers to Old Questions. Filadélfia: Xlibris Press, 1-15.

Alexander, David E. (2006), "Globalization of Disaster: Trends, problems and dilemmas”, Journal of International Affairs, 59(2), 1-22.

Alexander, David E. (2008), "Mainstreaming Disaster Risk Management", in Lee Bosher (org.), Hazards and the Built Environment: Attaining built-in resilience. Londres: Taylor \& Francis, 20-36.

Alexander, David E. (2010), "The L'Aquila Earthquake of 6 April 2009 and Italian Government Policy on Disaster Response", Journal of Natural Resources Policy Research, 2(4), 325-342.

Alexander, David E. (2011), "Mortality and Morbidity Risk in the L'Aquila, Italy, Earthquake of 6 April 2009 and Lessons to Be Learned”, in Robin Spence; Emily So e Charles Scawthorn (orgs.), Human Casualties in Earthquakes - Progress in Modelling and Mitigation. Advances in Natural and Technological Hazards Research, vol. 29. Berlin: Springer, 185-198.

Ammann, Walter J. (2006), "Risk Concept, Integral Risk Management and Risk Governance”, in Walter J. Ammann; Stefanie Dannenmann e Laurent Vulliet (orgs.), Risk 21: Coping with Risks Due to Natural Hazards in the 21: Century. Londres: Taylor \& Francis, 3-23.

Angotti, Thomas (1977), "Playing Politics with Disaster: The earthquakes of Friuli and Belice (Italy)”, International Journal of Urban and Regional Research, 1, 327-331. 
Avallone, Eugene A.; Baumeister III, Theodore; Sadegh, Ali (2007), Marks' Standard Handbook for Mechanical Engineers. New York: McGraw-Hill [11. ${ }^{a}$ ed.].

Aysan Yasemin; Davis, Ian (orgs.) (1992), Disasters and the Small Dwelling: Perspectives for the UN IDNDR. London: James \& James.

Barthes, Roland (2009), Mythologies. London: Vintage.

Bauman, Zygmunt (2001), Community: Seeking safety in an insecure world. Cambridge: Polity Press.

Birkmann, Jörn (org.) (2006), Measuring Vulnerability to Natural Hazards: Towards disaster resilient societies. Tokyo: United Nations University Press.

Birkmann, Jörn; von Teichman, Korinna (2010), "Integrating Disaster Risk Reduction and Climate Change Adaptation: Key challenges - scales, knowledge, and norms", Sustainability Science, 5, 171-184.

Briggs, John (2007), “The Use of Indigenous Knowledge in Development: Problems and challenges”, Progress in Development Studies, 7, 183-199.

Brislin, Ronald W. (1980), "Cross-Cultural Research Methods: Strategies, problems, applications”, in Irwin Altman; Amos Rapoport; Joachim F. Wohlwill (orgs.), Human Behavior and Environment, Vol. 4 - Environment and Culture. New York: Plenum Press, 47-82.

Calvi, G. M.; Spaziante, V. (2009), "Reconstruction between Temporary and Definitive: The CASE project”, Progettazione Sismica, 03, 221-250.

Dell'Osso, L.; Carmassi, C.;Massimetti, G.; Daneluzzo, E.; Di Tommaso, S.; Rossi, A. (2011), "Full and Partial PTSD among Young Adult Survivors 10 Months after the L'Aquila 2009 Earthquake: Gender differences”, Journal of Affective Disorders, 131(1-3), 79-83.

Eco, Umberto (1978), A Theory of Semiotics. Bloomington IN: Indiana University Press.

Enarson, Elaine; Morrow, Betty Hearn (orgs.) (1998), The Gendered Terrain of Disaster: Through women's eyes. Westport, CT: Greenwood.

Fothergill, Alice (2000), "Knowledge Transfer between Researchers and Practitioners", Natural Hazards Review, 1(2), 91-98.

Furedi, Frank (2004), Therapy Culture: Cultivating vulnerability in an uncertain age. London: Routledge.

Gheradi, Silvia (1998), “A Cultural Approach to Disasters”, Journal of Contingencies and Crisis Management, 6(2), 80-83.

Hewitt, Kenneth (1983), "The Idea of Calamity in a Technocratic Age”, in Kenneth Hewitt (org.), Interpretations of Calamity. London: Unwin-Hyma, 3-32.

Horlick-Jones, Tom (1995), "Modern Disasters as Outrage and Betrayal”, International Journal of Mass Emergencies and Disasters, 13(3), 305-315.

IFRCRCS (International Federation of Red Cross and Red Crescent Societies) (2010), World Disasters Report 2010. Focus on Urban Risk. Genebra: IFRCRCS. 
Jung, Carl Gustav (org.) (1964), Man and His Symbols. New York: Aldus Books.

Manyena, Siambabala Bernard (2006), "The Concept of Resilience revisited”, Disasters, 30(4), 434-450.

Massey, Douglas S. (1996), “The Age of Extremes: Concentrated affluence and poverty in the twenty-first century", Demography, 33(4), 395-412.

Mercer, Jessica; Dominey-Howes, Dale; Kelman, Ilan; Lloyd, Kate (2007), “The Potential for Combining Indigenous and Western Knowledge in Reducing Vulnerability to Environmental Hazards in Small Island Developing States”, Environmental Hazards, 7(4), 245-256.

Mercer, Jessica; Kelman Ilan; Taranis, Lorin; Suchet-Pearson, Sandie (2010), "Framework for Integrating Indigenous and Scientific Knowledge for Disaster Risk Reduction”, Disasters, 34(1), 214-239.

Purchase, Iain F. H.; Slovic, Paul (1999), “Quantitative Risk Assessment Breeds Fear”, Human and Ecological Risk Assessment, 5, 445-453.

Quarantelli, Enrico Louis (1997), "Problematical Aspects of the Information/Communication Revolution for Disaster Planning and Research: Ten non-technical issues and questions", Disaster Prevention and Management, 6(2), 94-106.

Russo, Giovanni (1955), Baroni e contadini. Bari: Universale Laterza.

Saunier, Richard E. (1999), "Sustainable Development, Global Sustainability”, in David E. Alexander e Rothes Whitmore Fairbridge (orgs.), Encyclopedia of Environmental Science. Dordrecht: Kluwer, 587-592.

Schoemaker, Paul J. H. (1993), "Multiple Scenario Development: Its conceptual and behavioral foundation”, Strategic Management Journal, 14(3), 193-213.

Simon, Herbert A. (1956), "Rational Choice and the Structure of the Environment", Psychological Review, 63, 129-138.

Slovic, Paul; Gregory, Robin (1999), "Risk Analysis, Decision Analysis and the Social Context for Risk Decision Making”, in James Shanteau, Barbara A. Mellers e David A. Schum (orgs.), Decision Science and Technology: Reflections on the contributions of Ward Edwards. Norwell, MA: Kluwer, 353-365.

Stucchi, Massimiliano; Meletti, Carlo; Manfredi, Gaetano; Dolce, Mauro (orgs.) (2009), "L’Aquila, April 6th 2009, 3:32am", Progettazione Sismica, 03, 1-256.

UNISDR (United Nations International Strategy for Disaster Reduction) (2005), Hyogo Framework for Action 2005-2015: Building the resilience of nations and communities. Genebra: UNISDR.

UNISDR (United Nations International Strategy for Disaster Reduction) (2009), Strengthening Climate Change Adaptation through Effective Disaster Risk Reduction. ISDR Briefing Note 03. Genebra: UNISDR. Consultado em http://www.unisdr.org/ preventionweb/files/16861_ccbriefingnote3.pdf.

Weichselgartner, Juergen (2001), "Disaster Mitigation: The concept of vulnerability revisited”, Disaster Prevention and Management, 10(2), 85-94. 
White, Gilbert F. (1974), "Natural Hazards Research: Concepts, methods, and policy implications”, in Gilbert F. White (org.), Natural Hazards: Local, national and global. New York: Oxford University Press, 3-16.

Wisner, Ben (2001), "Risk and the Neoliberal State: Why post-Mitch lessons didn't reduce El Salvador's earthquake losses”, Disasters, 25(3), 251-268. 